\title{
Measurement of faecal steroids for monitoring ovarian function in New World primates, Callitrichidae
}

\author{
M. Heistermann, S. Tari and J. K. Hodges \\ Department of Reproductive Biology, German Primate Centre, Kellnerweg 4, 37077 Göttingen, \\ Germany
}

\begin{abstract}
Measurement of immunoreactive progesterone, pregnanediol and oestradiol in faeces collected throughout ovarian cycles in three species of callitrichid primates is reported. Faecal hormone concentrations were compared with plasma progesterone profiles during $\mathrm{PGF}_{2 \alpha^{-}}$ controlled $(n=7)$ and natural $(n=8)$ cycles in Callithrix jacchus and Saguinus fuscicollis, respectively, and with urinary oestrone conjugates during five cycles in Saguinus oedipus. Unconjugated steroids, which predominated over enzyme hydrolysable conjugates in samples from all species, were used to generate cycle profiles. According to results from HPLC, oestrone and oestradiol accounted for virtually all oestrogen immunoreactivity, and oestradiol most often predominated, whereas large amounts of nonspecific immunoreactivity were detected by both progesterone and pregnanediol assays. Faecal progestins were excreted in a cyclic manner in all species; luteal phase values were on average five- to tenfold higher than corresponding follicular phase values. Significant increases in mean amounts of faecal progestins were seen within $48 \mathrm{~h}$ of the post-ovulatory rise in plasma progesterone. Although a similar trend was also seen for faecal oestradiol, a clear and consistent luteal phase increase was seen only in Callithrix jacchus and this generally occurred later than that of progestins. The results indicate that faecal progestin analysis provides a useful method for noninvasive reproductive assessment in callitrichid primates. In particular, measurement of immunoreactive pregnanediol enables a multispecies application of a single assay methodology for comparative studies on callitrichid reproductive function.
\end{abstract}

\section{Introduction}

Over the last 10 years, noninvasive methods for determining reproductive status have been important in facilitating studies in a wide variety of disciplines including biomedical research, behavioural ecology and conservation biology. The predominant method for endocrine monitoring of reproductive status has been (and still is) urinary hormone analysis, and measurement of steroid metabolites in urine has provided valuable information on ovarian cyclicity and pregnancy in a wide variety of mammalian species (see Lasley, 1985; Hodges, 1992, in press).

More recently, however, there has been increasing interest in the application of faecal hormone analysis as an additional or alternative approach to noninvasive endocrine assessment, primarily owing to the relative ease of sample collection from animals in group situations or in their natural habitat (Safar-Hermann et al., 1987; Wasser et al., 1988, 1991; Bamberg et al., 1984, 1991; Lasley and Kirkpatrick, 1991 for review). A number of studies have shown the presence of measurable amounts of reproductive steroids in faeces of primates (Risler et al., 1987; Wasser et al., 1988; Perez et al., 1988; Ziegler et al., 1989; Bamberg et al., 1991) and described improved methods for their extraction and immunological detection (Wasser et al., 1991;

Received 5 January 1993.
Shideler et al., 1993). However, with the exception of yellow baboons (Wasser et al., 1991) and cynomolgus monkeys (Shideler et al., 1993), there is no detailed information describing patterns of faecal steroid excretion throughout ovulatory cycles from which the reliability of faecal hormone measurements for determining ovarian function can be critically assessed.

The present study was conducted to evaluate the use of faecal hormone determinations for monitoring the ovarian cycle in callitrichid primates. Apart from the importance of certain species in biomedical research, the family Callitrichidae is the subject both of interest with regard to social regulation of female fertility (Abbott, 1984; Heistermann et al., 1989) and of concern owing to the endangered status of several species in the wild (Mittermeier et al,, 1988). As these primates exhibit few, if any, clearly visible signs of reproductive status, the application of endocrine monitoring methods has usually been necessary. Although urinary hormone analysis has been invaluable in this regard, species variation in the qualitative nature of urinary steroid metabolites (see, for example, Hodges and Eastman, 1984; Heger and Neubert, 1987) has imposed limitations on the inter-species applicability of individual assays. Information on the potential of faecal hormone analysis for monitoring reproductive status in Callitrichidae or indeed any other New World primate is not available.

The study described here was therefore carried out with the following specific objectives: (i) to establish and validate 
methods for the extraction and determination of reproductive steroids in faeces of callitrichid primates and (ii) to provide comparative data on the pattern of faecal steroid excretion throughout ovarian cycles in three species, namely the common marmoset, Callithrix jacchus, the saddle-back tamarin, Saguinus fuscicollis and the cotton-top tamarin, Saguinus oedipus.

\section{Materials and Methods}

\section{Animals}

Adult female Callithrix jacchus ( $n=4$ ) and Saguinus fuscicollis $(n=3)$ were housed in the Primate facilities of the German Primate Centre under a $12 \mathrm{~h}$ light: $12 \mathrm{~h}$ dark lighting regimen, in rooms maintained within a temperature and humidity range of $25 \pm 1^{\circ} \mathrm{C}$ and $60 \pm 5 \%$, respectively. Animals received primate pellets (variously supplemented with fruit, vegetables and a vitamin and mineral mix) once a day and water ad libitum. Saguinus oedipus ( $n=2$ ) were maintained in the primate colony at the University of Bielefeld under conditions described by Heistermann et al. (1989). Callithrix jacchus females were housed with intact males and cyclic ovarian function was maintained by the application of a luteolytic dose of PGF $_{2 \alpha}$ during the midluteal phase (Summers et al., 1985). Saguinus fuscicollis females were kept with vasectomized males and female Saguinus oedipus were maintained in family groups without a breeding male.

\section{Sample collection}

Faecal samples were collected 5-7 days a week for at least one but not more than three ovarian cycles for an individual animal. In total, samples were collected from seven, eight and five cycles from Callithrix jacchus, Saguinus fuscicollis and Saguinus oedipus, respectively. Samples were collected between 07:00 and 08:00 h by separating females from their partner or family members and keeping them in isolation in the home cage until they defaecated (usually less than $40 \mathrm{~min}$ ). Faeces were collected on plastic sheets positioned under the cage and constructed in a way to minimize contamination with urine. A $5-10 \mathrm{~g}$ faecal sample was transferred to a plastic tube and stored at $-20^{\circ} \mathrm{C}$ until analysed.

In addition, blood samples $(0.2 \mathrm{ml})$ taken from the femoral vein of non-sedated animals, were collected two to three times per week from Callithrix jacchus and Saguinus fuscicollis. The plasma was stored at $-20^{\circ} \mathrm{C}$ before being assayed for progesterone to confirm ovulation and provide an independent assessment of the stage of the cycle. As collection of regular blood samples from Saguinus oedipus was not possible, urine samples were collected at the same time as faecal samples and stored $\left(-20^{\circ} \mathrm{C}\right)$ for later measurement of oestrone conjugates as an indicator of luteal function (see below).

\section{Sample extraction and chromatography}

Faecal samples (total amount collected) were lyophilized for $24-48 \mathrm{~h}$, and the resulting dried pellets were pulverized with a pestel and mortar and all solid inert materials (for example seeds and rough dietary fibre) were removed. A sample of the powder representing $0.05-0.10 \mathrm{~g}$ dry weight was placed in a $25 \mathrm{ml}$ polypropylene tube and a total of 10000 c.p.m. ${ }^{3}$ H]progesterone (Amersham Buchler, Braunschweig) was added to monitor extraction efficiency. $\left[{ }^{3} \mathrm{H}\right]$ progesterone was used routinely as recovery tracer irrespective of which hormone was to be assayed, as initial studies showed extraction efficiencies to be similar for all unconjugated steroids tested (progesterone: $82-94 \%$; pregnanediol: $86-95 \%$; oestradiol: $82-95 \%$ ). Recovery values between species were not different and the overall mean recovery value for all samples extracted was $89.1 \pm 1.0 \%(\bar{x} \pm$ SEM, $n=418$ ).

Steroids were extracted from the faeces according to a modification of the method described by Wasser et al. (1991). Ethanol:acetone ( $5 \mathrm{ml} ; 4: 1 \mathrm{v}: \mathrm{v})$ was added to the sample; the mixture was vortexed for $15 \mathrm{~min}$ and after centrifugation $(2600 \mathrm{~g}$ for $15 \mathrm{~min}$ ), the supernatant was decanted into a $15 \mathrm{ml}$ glass tube. The faecal pellet was re-extracted by vortexing for $5 \mathrm{~min}$ with $2 \mathrm{ml} 80 \%$ ethanol, recentrifuged and the supernatants were combined. The volume of the mixture was reduced under nitrogen to approximately $3 \mathrm{ml} ; \mathrm{I}$ ml distilled water was added and the solution vortexed and further reduced in volume to approximately $1 \mathrm{ml}$ (step 1 ). Unconjugated steroids were then extracted into $5 \mathrm{ml}$ diethylether and after evaporation to dryness, steroids were reconstituted in $1 \mathrm{ml}$ absolute methanol (step 2). The radioactivity of a $50 \mu \mathrm{l}$ portion of the extract was measured to determine extraction efficiency; the remaining methanolic extract was stored at $-20^{\circ} \mathrm{C}$ until assayed. Initial studies on the effect of quenching on counting efficiency determined by counting different volumes of extract $(25-200 \mu \mathrm{l})$ in $3 \mathrm{ml}$ scintillation fluid showed that quenching was not observed in volumes of less than $100 \mu \mathrm{l}$. A volume of $50 \mu \mathrm{l}$ was therefore chosen to determine recovery.

The relative abundance of steroids present in faeces as conjugates was assessed by extracting selected samples from the follicular and luteal phase in each species, and taking both organic and residual aqueous phases (step 2, see above) for further analysis. The aqueous residue was adjusted to $\mathrm{pH} 5$ with $0.1 \mathrm{~mol} \mathrm{HCl} \mathrm{l} \mathrm{I}^{-1}$ and incubated for $18-20 \mathrm{~h}$ at $37^{\circ} \mathrm{C}$ with $50 \mu \mathrm{l} \beta$-glucuronidase/sulfatase (Type H-5, No. G-1512; Sigma Chemicals, Deisenhofen; containing 2500 Fishman U $\beta$ glucuronidase and $200 \mathrm{U}$ sulfatase activity per $50 \mu \mathrm{l}$ ). After hydrolysis the free steroids were extracted with $5 \mathrm{ml}$ diethylether, the ether evaporated to dryness and the extract reconstituted in $1 \mathrm{ml}$ methanol. Extraction and hydrolysis efficiencies were monitored by adding tritiated conjugated steroids (10 000 c.p.m. $\left[{ }^{3} \mathrm{H}\right]$ pregnanediol-3-glucuronide for progestin measurement; $\left[{ }^{3} \mathrm{H}\right]$ oestrone-3-glucuronide for oestrogen measurement) to the faecal sample before the initial ethanolacetone extraction. Overall recoveries of conjugates after enzyme hydrolysis were similar in all species with mean values of $57.5 \pm 2.8 \%$ for $\left[{ }^{3} \mathrm{H}\right]$ pregnanediol-glucuronide $(n=53)$ and $70.3 \pm 1.1 \%$ for $\left[{ }^{3} \mathrm{H}\right]$ oestrone-glucuronide $(n=74)$. The lower recovery of conjugated steroids appears to be due largely to a relatively inefficient initial extraction step (step 1) rather than to procedural losses at step 2 or to ineffective hydrolysis (tested, but data not shown).

\section{High pressure liquid chromatography}

Luteal phase faecal extracts from two animals of each species were subjected to HPLC to examine the distribution of steroid 
immunoreactivity and specificity of measurement for the diverse assays (see below). Steroids were separated by reverse phase HPLC using a Nova-Pak C18 column $(3.9 \mathrm{~mm} \times 75 \mathrm{~mm}$; Millipore $\mathrm{GmbH}$, Eschborn) and acetonitrile:water mixtures of either 30:70 (oestrogens) or 40:60 (progestins) as eluents. Faecal methanol extracts $(200 \mu \mathrm{l})$ were combined with 10000 c.p.m. each of a mixture of $\left[{ }^{3} \mathrm{H}\right]$ steroids (oestrone, oestradiol and oestriol for HPLC of oestrogens; 17 $\alpha$-hydroxyprogesterone, 20a-hydroxypregnenone, progesterone and pregnanediol for HPLC of progestins) as markers to indicate steroid elution positions. Sample extracts were then further purified with SepPak C-18 cartridges (Waters Ass., Milford), reconstituted in $200 \mu \mathrm{l}$ acetonitrile:water (50:50, v:v) and filtered through a $0.2 \mu \mathrm{m}$ membrane before loading $50 \mu \mathrm{l}$ onto the column. Fractions, $1 \mathrm{ml}$, were collected at intervals of $1 \mathrm{~min}$. Aliquots $(100 \mu \mathrm{l})$ of the fractions were counted directly for recovery and immunoreactivity was determined in the appropriate oestrogen (total oestrogen, oestradiol) or progestin (progesterone, pregnanediol) immunoassays.

\section{Hormone assays}

Progesterone. Progesterone in plasma was determined by a direct, nonextraction enzymeimmunoassay using an antiserum raised in sheep against progesterone-11- $\alpha$-hemisuccinate-BSA and alkaline phosphatase linked to progesterone-11-glucuronide as enzyme conjugate. The assay has been previously described in detail for use in the marmoset monkey by Hodges et al. (1988). The method was further validated for progesterone determination in Saguinus fuscicollis by demonstrating parallelism between displacement curves from standards and dilutions of plasma. Sensitivity of the assay, defined as the hormone concentration at $90 \%$ binding, was $6 \mathrm{pg}$ per well and intra- and interassay coefficients of variation calculated from repeated measurement of a marmoset plasma pool were below $10 \%$ and $13 \%$, respectively.

The same assay procedure was used for measurement of progesterone immunoreactivity in fractions recovered from HPLC and in faecal methanolic extracts following appropriate dilution in assay buffer $\left(0.02 \mathrm{~mol}\right.$ Tris-buffered saline $\mathrm{I}^{-1}$ with $0.1 \%$ BSA, $\mathrm{pH}$ 7.2).

Pregnanediol. Immunoreactive pregnanediol was determined in a microtitre plate enzymeimmunoassay using the streptavidin-biotin technique described by Meyer et al. (1990). The assay uses a hormone specific antiserum raised in a rabbit against pregnanediol-3-glucuronide-BSA and sheep anti-rabbit IgG (No. R-9754 Sigma Chemie, Deisenhofen) as coating antibody. Pregnanediol was used as standard, although the assay was originally designed to measure the glucuronide. Crossreactivity of the primary antiserum with the free steroid was $22 \%$. For crossreactivity values with other steroids see Hodges and Green (1989). Biotinylated pregnanediol-3-glucuronide (prepared by E. Möstl, Vienna) in conjunction with peroxidase (POD) labelled streptavidin (No. S-5512, Sigma Chemie) was used as conjugate. In brief, faecal extracts were diluted with $0.04 \mathrm{~mol}$ phosphate-buffered saline $\mathrm{I}^{-1}$ containing $0.1 \% \mathrm{BSA}$ (PBS, $\mathrm{pH} \mathrm{7.0)}$ and $50 \mu \mathrm{l}$ aliquots taken in duplicate to assay. Unknowns and pregnanediol standards $(50 \mu \mathrm{l}, 39-10000 \mathrm{pg}$ per well) were combined with labelled pregnanediol glucuronide
$(50 \mu \mathrm{l})$ and antiserum $(50 \mu \mathrm{l})$, mixed thoroughly, sealed with plastic film and incubated overnight at $4{ }^{\circ} \mathrm{C}$. After incubation the plates were washed four times with distilled water containing $0.05 \%$. Tween 20 , blotted dry and $100 \mu \mathrm{l}$ (20 ng) of streptavidinPOD in assay buffer was added to each well. The plates were sealed and incubated at room temperature in a dark, humid chamber for $15 \mathrm{~min}$, after which they were washed again four times. Substrate solution $(150 \mu \mathrm{l}$, including $0.025 \%$ tetramethylbenzidine and $0.05 \% \mathrm{H}_{2} \mathrm{O}_{2}$ ) was added and the plates incubated at room temperature in darkness for another $15-20 \mathrm{~min}$. The enzyme reaction was stopped by the addition of $50 \mu \mathrm{l} 2 \mathrm{~mol}$ $\mathrm{H}_{2} \mathrm{SO}_{4} 1^{-1}$ and absorbance measured at $450 \mathrm{~nm}$ on an automatic plate reader. The amount of pregnanediol in the sample was calculated automatically by a reader linked computer program (MikroTEK Laborsysteme GmbH, Overath) using the standard curve as reference. Sensitivity of the assay was 65 pg per well.

Oestradiol. Oestradiol immunoreactivity in faecal extracts was determined by radioimmunoassay (Hodges et al., 1983) using an antiserum raised in rabbits against oestradiol-6-carboxymethyl-BSA (donation from H.O. Hoppen, Hannover) and $\left[{ }^{3} \mathrm{H}\right]$ oestradiol (10 000 c.p.m.; Amersham Buchler, Braunschweig) as tracer. The antiserum showed the following crossreactivities relative to oestradiol (100\%): 4-hydroxyoestradiol: $52 \%$; 2 hydroxyoestradiol: $22 \%$; 4 -hydroxyoestrone: $2.8 \%$; oestrone: 1.8\%; oestriol: $1.0 \%$; $17 \alpha$-oestradiol: $0.9 \%$ and $\leqslant 0.1 \%$ for all other steroids tested (including progesterone and pregnanediol). Faecal extracts were diluted in assay buffer $\left(0.1 \mathrm{~mol}\right.$ PBS $\mathrm{I}^{-1}$ containing $0.1 \%$ gelatine; $\mathrm{pH} 7.2$ ) and $100 \mu \mathrm{l}$ aliquots were assayed in duplicate with oestradiol standards ( $100 \mu \mathrm{l}, 3.9-$ $1000 \mathrm{pg}$ per tube) in an overnight incubation at $4^{\circ} \mathrm{C}$. Dextrancoated charcoal $(0.05 \%$ and $0.5 \%$, respectively) was used to separate free from bound steroid. Sensitivity of the assay was 8 pg per tube.

Oestrone conjugates. Urinary oestrone conjugates were measured by a direct radioimmunoassay described by Heistermann et al. (1989). Sensitivity of the assay was $14 \mathrm{pg}$ per tube and intra- and interassay coefficients of variation were below $7 \%$. Variation in fluid intake and output was compensated for by estimating the creatinine $(\mathrm{Cr})$ concentration of each urine sample (see Heistermann et al, 1989) and hormone concentrations were expressed as $\mu \mathrm{g} \mathrm{mg}^{-1}$ creatinine.

Total oestrogens. Oestrogen immunoreactivity in the fractions collected from HPLC was measured by radioimmunoassay using a nonspecific antibody raised in rabbits against oestradiol17-hemisuccinate-BSA (donation from $\mathrm{H}$. Meyer, FreisingWeihenstephan). The crossreactivities of the antiserum relative to oestradiol $(100 \%)$ were $110 \%$ for oestrone, $80 \%$ for $17 \alpha$ oestradiol, $2.5 \%$ for oestriol, $0.4 \%$ for oestradiol-17-glucuronide and $<0.1 \%$ for all other steroids tested. Oestradiol was used as a standard (100 $\mu \mathrm{l}, 3.9-1000 \mathrm{pg}$ per tube) and $\left[{ }^{3} \mathrm{H}\right]$ oestradiol as tracer (100 $\mu \mathrm{l}, 10000$ c.p.m.). The assay procedure was the same as described for the specific oestradiol measurement (see above). Sensitivity of the assay was $10 \mathrm{pg}$ per tube and intra- and interassay coefficients of variation calculated on the repeated measurement of an oestradiol pool in assay buffer were below $7 \%$ and $16 \%$, respectively. 
Validation of faecal steroid measurements. Validation procedures were carried out for the measurement of progesterone, pregnanediol and oestradiol in extracts of faeces from each species as follows.

Serial dilutions of methanolic faecal extracts of follicular and luteal phase samples gave displacement curves parallel to those obtained with the appropriate standards. The range of dilutions varied between 1:100 and 1:64000 depending upon species, hormone and stage of cycle.

Accuracy was assessed by determining recovery of known amounts of pure steroid (five doses) added in triplicate to faeces before their extraction. Mean \pm SD recovery values ranged from $85.3 \pm 10.2 \%$ for progesterone (Callithrix jacchus) to $116.9 \pm 4.6 \%$ for pregnanediol (Saguinus oedipus); recovery values for all other species and hormones were within these figures.

Precision of all assays was assessed by replicate determinations of quality control pools obtained from pulverized faecal samples from each species. Irrespective of species and hormone measured, intra-assay coefficients of variation ranged between 5.5 and $13.4 \%$. Corresponding values for interassay coefficients of variation ranged between 6.1 and $16.3 \%$.

Specificity of hormone measurement was assessed by HPLC analysis of luteal phase faecal samples. The presence of progesterone and pregnanediol was confirmed by the co-elution of immuno- and radioactivity, but substantial amounts of additional immunoreactivity were detected, indicating that the measurement of these steroids was nonspecific. Values reported throughout this study are therefore expressed as progesterone or pregnanediol immunoreactivity. The HPLC profiles for a faecal sample extract from Saguinus fuscicollis (Fig. 1) are typical of those obtained for all species.

Analysis of HPLC fractions in the total oestrogen assay indicated that oestradiol and oestrone were the principal immunoreactive oestrogens and that oestradiol was usually the more abundant (see Fig. 1 for Saguinus fuscicollis). It is for this reason, together with the lack of a noticeable difference between cycle profiles for oestradiol and oestrone, that only data for oestradiol are reported. Although subsequent measurement of HPLC fractions using the specific oestradiol antibody revealed a single immunoreactive peak co-eluting with oestradiol tracer, faecal oestradiol values obtained after HPLC were invariably lower than corresponding values obtained by direct assay of the faecal extract. The reason for this is not clear, but oestradiol determinations are also assumed to reflect total oestradiol immunoreactivity.

\section{Analysis of data}

Plasma progesterone profiles were used to define the stage of cycle in Callithrix jacchus and Saguinus fuscicollis. Accordingly, in Callithrix jacchus a rise in progesterone to a value above $10 \mathrm{ng}$ $\mathrm{ml}^{-1}$ was assumed to occur one day after ovulation (Harlow et al., 1983) and this value was also used to define the onset and end of the luteal phase (Harlow et al., 1983; Hodges et al., 1988). Similar information is not available for Saguinus fuscicollis, although Tardif and Ziegler (1992) have arbitrarily defined ovulation as occurring the day before progesterone increases above $20 \mathrm{ng} \mathrm{ml}^{-1}$. Our data support the use of this higher
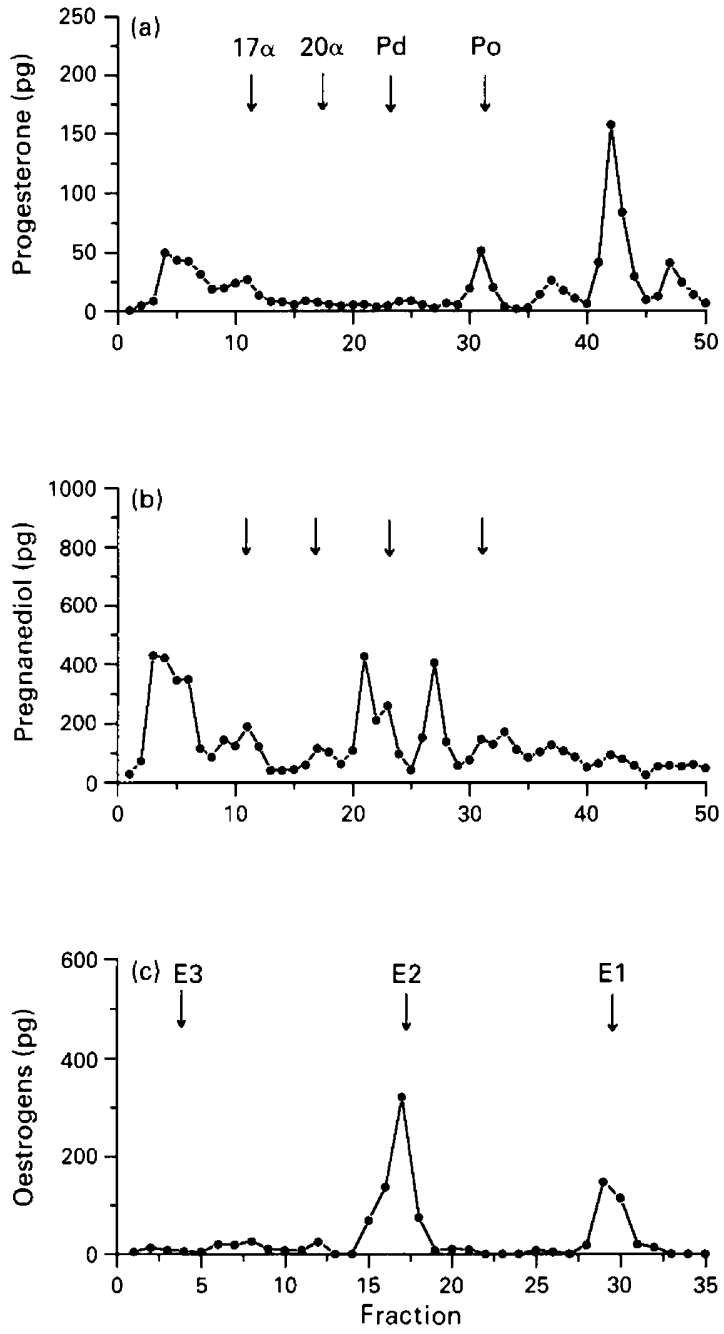

Fig. 1. HPLC separation of progestins ( $a$ and b) and oestrogens (c) in a luteal phase faecal extract from Saguinus fuscicollis. Immunoreactivity measured in each fraction is compared with peak recovery of radioactive markers indicated by the arrows. $17 \alpha$ : $17 \alpha$-hydroxyprogesterone;

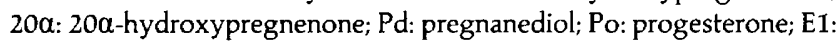
oestrone; E2: oestradiol; E3: oestriol.

progesterone value to indicate the onset and end of the luteal phase and this has been applied in the present study. Measurement of urinary oestrone conjugates to indicate ovarian cyclicity in Saguinus oedipus has been described by Ziegler et al. (1987) and Heistermann et al. (1989): concentrations increase at, or shortly after, the time of the urinary LH peak and remain high throughout the luteal phase.

Composite faecal hormone data have been normalized to the day of the defined plasma progesterone rise and, for Callithrix jacchus, the day of prostaglandin $\mathrm{F}_{2 a}$ injection. A threshold value of $3 \mathrm{SD}$ above the mean of the preceding follicular phase values was calculated to assess timing of the first significant increase in mean faecal steroid concentrations with respect to the progesterone rise in plasma. An increase in concentrations above this threshold value was taken to indicate a statistically significant rise $(P<0.01$; Sachs, 1975; Jeffcoate, 1983). 
Table 1. Enzyme hydrolysable steroid conjugates in faeces from three species of Callitrichidae

\begin{tabular}{|c|c|c|c|c|c|c|}
\hline \multirow[b]{2}{*}{ Steroid } & \multicolumn{2}{|c|}{ Callithrix jacchus } & \multicolumn{2}{|c|}{ Saguinus fuscicollis } & \multicolumn{2}{|c|}{ Saguinus oedipus } \\
\hline & $\begin{array}{l}\text { Follicular } \\
\text { phase }\end{array}$ & $\begin{array}{l}\text { Luteal } \\
\text { phase }\end{array}$ & $\begin{array}{l}\text { Follicular } \\
\text { phase }\end{array}$ & $\begin{array}{l}\text { Luteal } \\
\text { phase }\end{array}$ & $\begin{array}{l}\text { Follicular } \\
\text { phase }\end{array}$ & $\begin{array}{l}\text { Luteal } \\
\text { phase }\end{array}$ \\
\hline Progesterone & $\begin{array}{c}20.9 \pm 3.4 \\
(10)\end{array}$ & $\begin{array}{c}9.4 \pm 1.2 \\
(10)\end{array}$ & $\begin{array}{c}16.2 \pm 2.0 \\
(1 \bar{I})\end{array}$ & ${ }_{(I I)} 2.6$ & $10.0 \pm \frac{ \pm}{(7)} 1.9$ & $\begin{array}{c}6.8 \pm 1.3 \\
(10)\end{array}$ \\
\hline Pregnanediol & $\begin{array}{c}34.1 \pm 2.4 \\
(10)\end{array}$ & $\begin{array}{c}8.4 \pm 2.9 \\
(10)\end{array}$ & $11.7 \pm 2.6$ & $8.3 \pm 1.6$ & $25.4 \frac{ \pm}{(7)} 4.8$ & $\begin{array}{c}16.7 \pm 4.5 \\
(10)\end{array}$ \\
\hline Oestradiol & $\begin{array}{c}32.9 \pm 3.2 \\
(10)\end{array}$ & $\begin{array}{c}22.6 \pm 1.3 \\
(10)\end{array}$ & $\underset{(11)}{14.3 \pm 4.2}$ & $\begin{array}{c}18.9 \pm 4.4 \\
\quad(11)\end{array}$ & $\begin{array}{c}25.7 \pm 3.0 \\
(11)\end{array}$ & $\begin{array}{c}19.2 \pm 2.2 \\
\text { (1I) }\end{array}$ \\
\hline
\end{tabular}

Figures represent immunoreactivity measured in the hydrolysed aqueous residue (following ether extraction, step 2) expressed as a percentage of the total (i.e. hydrolysed aqueous plus ether extractable steroids). Values represent means \pm SEM; values in parentheses represent numbers of samples analysed.

\section{Results}

Free versus conjugated steroids in faeces

The proportions of total immunoreactive progesterone, pregnanediol and oestradiol detected as enzyme hydrolysable conjugates in faeces of three callitrichid species are shown (Table 1). Although figures vary considerably according to stage of cycle and hormone measured, unconjugated steroids predominated in all samples analysed. Thus in all three species approximately $85-95 \%$ of immunoassayable progesterone and pregnanediol during the luteal phase was accounted for by unconjugated steroids; corresponding values for the follicular phase were $65-90 \%$. Of the total oestradiol immunoreactivity, $65-85 \%$ was measured as free steroid, and values were similar during both stages of the cycle. On the basis of these findings measurements of unconjugated steroids were used in generating cycle profiles.

\section{Faecal hormone profiles}

Callithrix jacchus. An example is shown of the pattern of excretion of immunoreactive progesterone, pregnanediol and oestradiol in faeces during two consecutive $\mathrm{PGF}_{2 \alpha}$-abbreviated ovarian cycles in a female common marmoset (Fig. 2a). Each of the three steroids measured in faeces was excreted in a cyclic manner corresponding to the plasma progesterone profile, and highest concentrations were measured during the luteal phase of the cycle (plasma progesterone $>10 \mathrm{ng} \mathrm{ml}^{-1}$ ). Quantitatively, immunoreactive pregnanediol predominated, with concentrations exceeding those of progesterone and oestradiol by a factor of 15-20. Although differences between mean follicular and luteal phase values were generally greater with measurements of progesterone, there was less variation between individuals in concentrations of pregnanediol.

Composite profiles for pregnanediol and oestradiol during a total of seven $\mathrm{PGF}_{2 \alpha}$-controlled cycles from four animals are shown (Fig. 3). As the profiles do not represent complete ovarian cycles, data have been aligned separately to the days of the increase in plasma progesterone and $\mathrm{PGF}_{2 \alpha}$ application. The low degree of individual and sample variation during the pre-ovulatory period (days -6 to -1 ) is evident for both hormones, and mean values range from 2.9 to $3.6 \mu \mathrm{g} \mathrm{g}^{-1}$ for pregnanediol and from 0.1 to $0.2 \mu \mathrm{g} \mathrm{g} \mathrm{g}^{-1}$ for oestradiol. Corresponding maximum mean luteal phase concentrations were $48.7 \mu \mathrm{g} \mathrm{g}^{-1}$ and $2.3 \mu \mathrm{g} \mathrm{g}^{-1}$ for pregnanediol and oestradiol, respectively, representing an approximately 15-20fold increase. With respect to the defined increase in progesterone in plasma, the first significant increase in mean faecal pregnanediol and oestradiol concentrations occurred on day 2 and 4 , respectively. The extent to which the faecal hormone measurements reflect corpus luteum function is also shown by the abrupt decline in concentrations of both hormones after injection of a luteolytic dose of $\mathrm{PGF}_{2 \mathrm{a}}$. Faecal oestradiol values fell to within the follicular phase range by $I$ day after $P F_{2 \alpha}$ injection, whereas a more gradual decline over 3 days was seen for pregnanediol.

Saguinus fuscicollis. Plasma progesterone and faecal progesterone, pregnanediol and oestradiol concentrations during three consecutive ovarian cycles in a female saddle-back tamarin are illustrated (Fig. 2b). The patterns of excretion of both faecal progestins correspond closely to that of circulating progesterone, and consistently low concentrations were measured during the inter-luteal (presumed follicular) phase and variable but clearly increased concentrations during the period of high plasma progesterone (presumed luteal phase).

Although faecal oestradiol concentrations were also generally higher after ovulation than during the follicular phase there was a high degree of sample-to-sample variation and the pattern throughout the cycle was less clearly defined. As in common marmosets, immunoreactive pregnanediol concentrations exceeded those of progesterone and oestradiol in all animals. Faecal progesterone concentrations were similar in Saguinus fuscicollis and Callithrix jacchus, but pregnanediol and oestradiol were excreted in considerably higher amounts in the former species.

Mean concentrations of faecal pregnanediol (eight cycles from three females) increased from follicular phase values (days -5 to -1 ) of $10-20 \mu \mathrm{g} \mathrm{g}^{-1}$ to maximum values of $80-100 \mu \mathrm{g} \mathrm{g}^{-1}$ within five days of the increase in plasma 

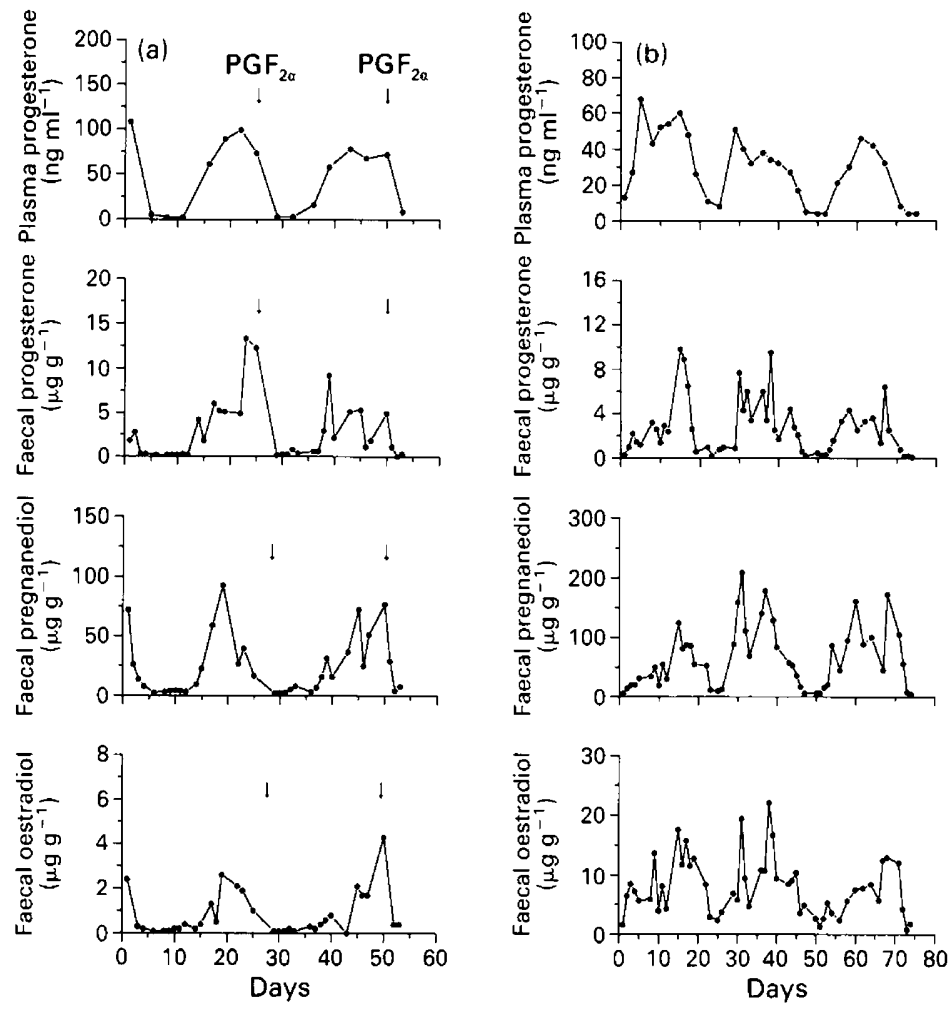

Fig. 2. Hormonal profiles of plasma progesterone and immunoreactive faecal progesterone, pregnanediol and oestradiol during consecutive ovarian cycles in (a) a female common marmoset and (b) a female saddle-back tamarin. Arrows in (a) indicate the days of $\mathrm{PGF}_{2 \alpha}$ application.

progesterone (Fig. 4). With respect to the latter, the first significant increase in mean faecal pregnanediol concentrations occurred on day 2. Although mean oestradiol concentrations were also high during the luteal phase, the composite profile revealed a high degree of day-to-day variability and failed to show any significant increase over follicular phase values $(P>0.05)$.

Saguinus oedipus. Data for three cycles from one of the two female Saguinus oedipus studied are shown (Fig. 5). Measurement of urinary oestrone conjugates was used to monitor ovarian function, with periods of high urinary oestrogen concentrations representing the post-ovulatory or luteal phase (Ziegler et al., 1987). The corresponding patterns of excretion of faecal progestins (progesterone and pregnanediol) and urinary oestrone conjugates indicate the potential of faecal analysis for monitoring luteal function. Faecal oestradiol concentrations also tended to be high during the luteal phase but the pattern was less clear than for faecal progestins. Profiles for all hormones measured were similar in the second female. As was seen in the two other callitrichid species, more pregnanediol was excreted into the faeces compared with the other two hormones.

\section{Discussion}

The present study provides the first detailed assessment of the use of faecal steroid analysis for monitoring ovarian function in
New World primates. The results show that measurement of unconjugated progestins and, to a lesser extent, oestrogens in faeces is a reliable method for documenting ovarian cycles in both marmosets and tamarins.

Measurements of unconjugated steroids were used to describe ovarian cycles as they appeared to predominate over conjugates in faecal extracts of all three species. Studies in humans and Old World primates have focused almost exclusively on measuring steroids in the unconjugated form (Adlercreutz and Martin, 1976; Risler et al., 1987; Wasser et al., 1991; Bamberg et al., 1991). The present data, however, indicate that although the majority of immunoassayable steroids in callitrichid faeces were present in the ether-extractable portion, substantial amounts (up to $35 \%$ ) of conjugated steroids were also detected. Ziegler $e t$ al. (1989) reported similar figures for the proportion of conjugated progestin metabolites in faeces of Saguinus oedipus. They also reported the measurement of oestrogen conjugates, but in contrast to the present study found that conjugates predominated over free steroid (up to $85 \%$ of total). Although there are several possible reasons for this discrepancy (arising from the use of widely differing experimental approaches), one in particular is that the measurement of Ziegler and co-workers accounted for all nonether-extractable conjugates, whereas in the study reported here, only enzyme hydrolysable forms of conjugates were detected. Incomplete enzymatic hydrolysis of excreted oestrogen conjugates (Bain et al., 1984; Hodges and Eastman, 1984; Ziegler et al., 1989) may thus have led to an underestimation of the proportion of faecal oestrogens present in the conjugated form. 

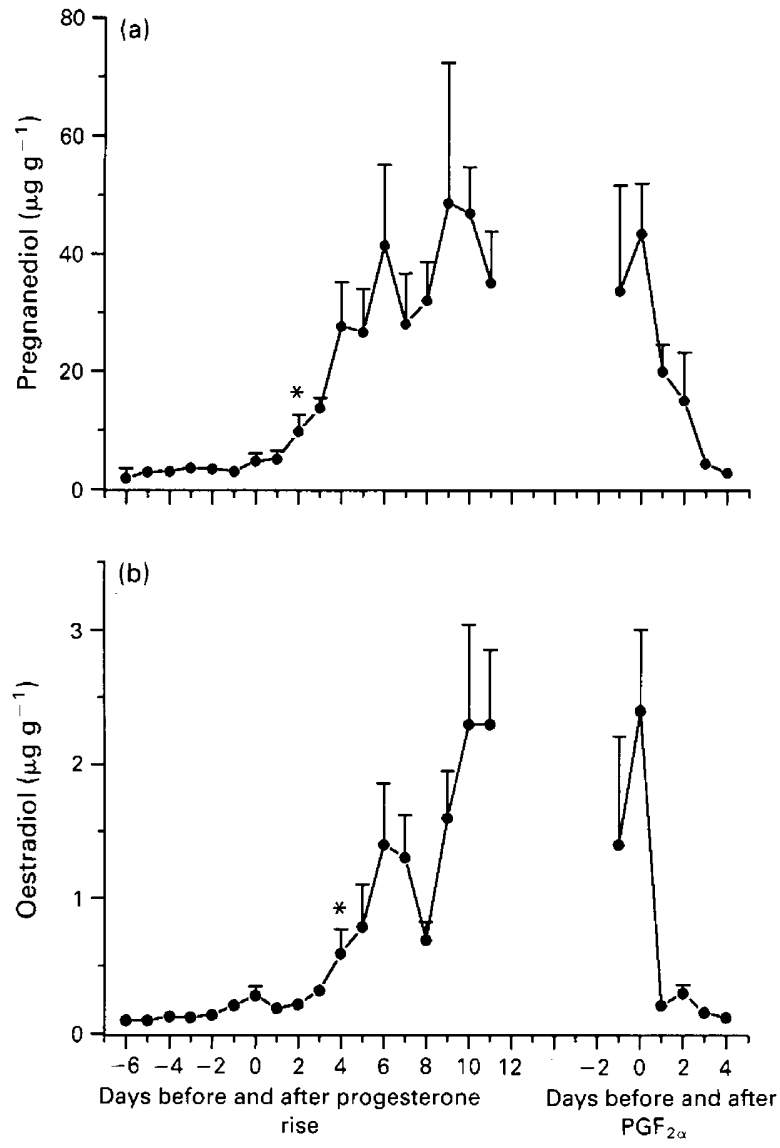

Fig. 3. Mean ( \pm SEM) concentrations of (a) faecal pregnanediol and (b) faecal oestradiol immunoreactivity in seven $\mathrm{PGF}_{2 \mathrm{a}}$-controlled ovarian cycles from four female common marmosets. Days are separately aligned to the day of the rise in plasma progesterone above a value of $10 \mathrm{ng} \mathrm{ml}^{-1}$ (=day 0); and to the day of $\mathrm{PGF}_{2 a}$ application. Asterisks indicate first significant luteal phase increase in values in comparison with follicular phase concentrations.

High concentrations of unconjugated oestrogens were nevertheless measured in callitrichid faeces. Oestrone and oestradiol accounted for virtually all of the immunoreactivity measured and although both were abundant, oestradiol generally predominated. Previous information on the measurement of oestrogens in New World primate faeces is limited to the study by Ziegler et al. (1989), in which the relative amounts of free oestrone and oestradiol were not clearly reported. From our initial tests, there seemed to be very little difference in the excretory patterns of the two hormones, and so further measurement of oestrone was discontinued. In the event that much higher concentrations of conjugated oestrogens are present in faeces than our results suggest, re-evaluation of the relative abundance of oestrogen metabolites and their relationship to ovarian function would be necessary.

In contrast to the results for oestrogens, HPLC of faecal progestins in samples from all three species clearly indicated the presence of substantial amounts of nonspecific immunoreactivity. Although the presence of progesterone and pregnanediol was confirmed, the HPLC data indicate that each steroid contributed less than $50 \%$ of the total immunoreactivity measured
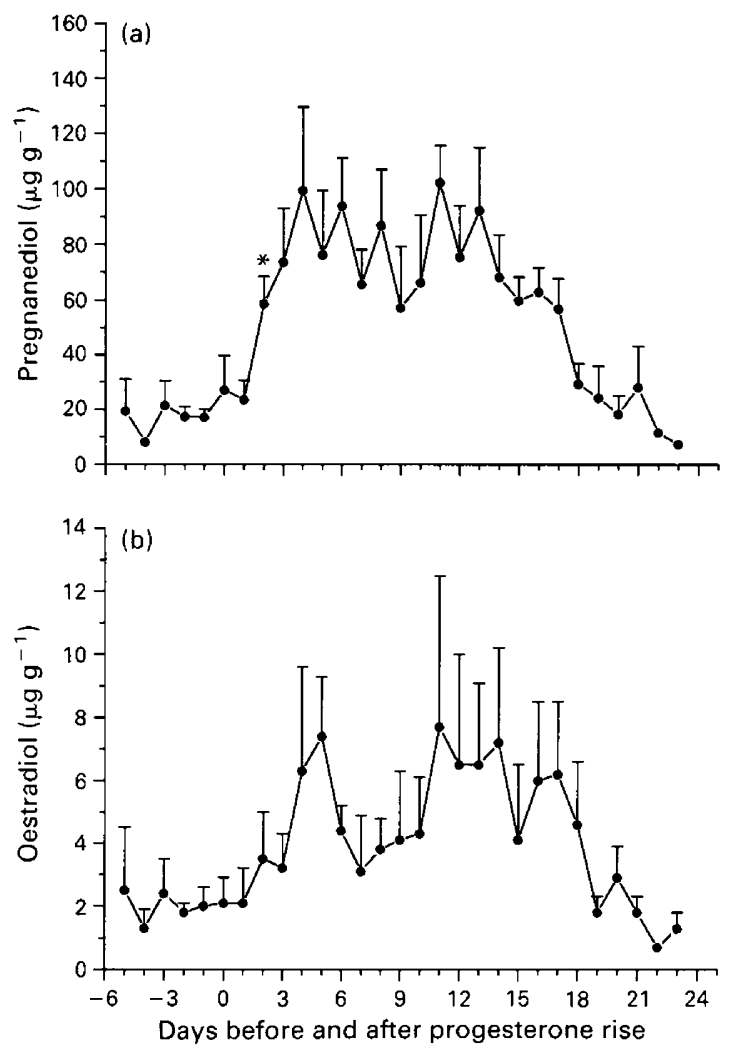

Fig. 4. Mean ( \pm SEM) concentrations of (a) faecal pregnanediol and (b) faecal oestradiol immunoreactivity in eight ovarian cycles from three female saddle-back tamarins. Days are aligned to the day of the rise in plasma progesterone above a value of $20 \mathrm{ng} \mathrm{m}^{-1}$ (=day 0). Asterisk indicates first significant luteal phase increase in values in comparison with follicular phase concentrations.

in each assay. The existence of a broad spectrum of progestin metabolites is not surprising and multiple peaks of radioactivity were reported after HPLC separation of faecal extracts in the radiometabolism study of Ziegler et al. (1989). Although the nature of the cross-reacting immunoreactive substances is unknown, their elution positions on HPLC were similar between species (this study) and between studies (see Ziegler et al., 1989), indicating that there are quantitatively important faecal progesterone metabolites that are common to both marmosets and tamarins. The finding that pregnanediol immunoreactivity predominated in all samples analysed and that its measurement provided a reliable indicator of luteal function in each species further suggests species similarities in the nature of faecal progestins in callitrichid primates. The successful monitoring of ovarian function by measurement of excreted faecal progestins is in contrast to the measurement of urinary progesterone metabolites which so far has been successfully applied only to Callithrix jacchus (Eastman et al., 1984; Heger and Neubert, 1987).

Irrespective of the assay used, the present study shows that measurement of faecal progestins provides reliable information on luteal function in both marmosets and tamarins. In contrast, the pattern of oestradiol excretion provides a clear reflection of ovarian function only in marmosets, although a similar pattern of high luteal phase concentrations was seen in all three species. 

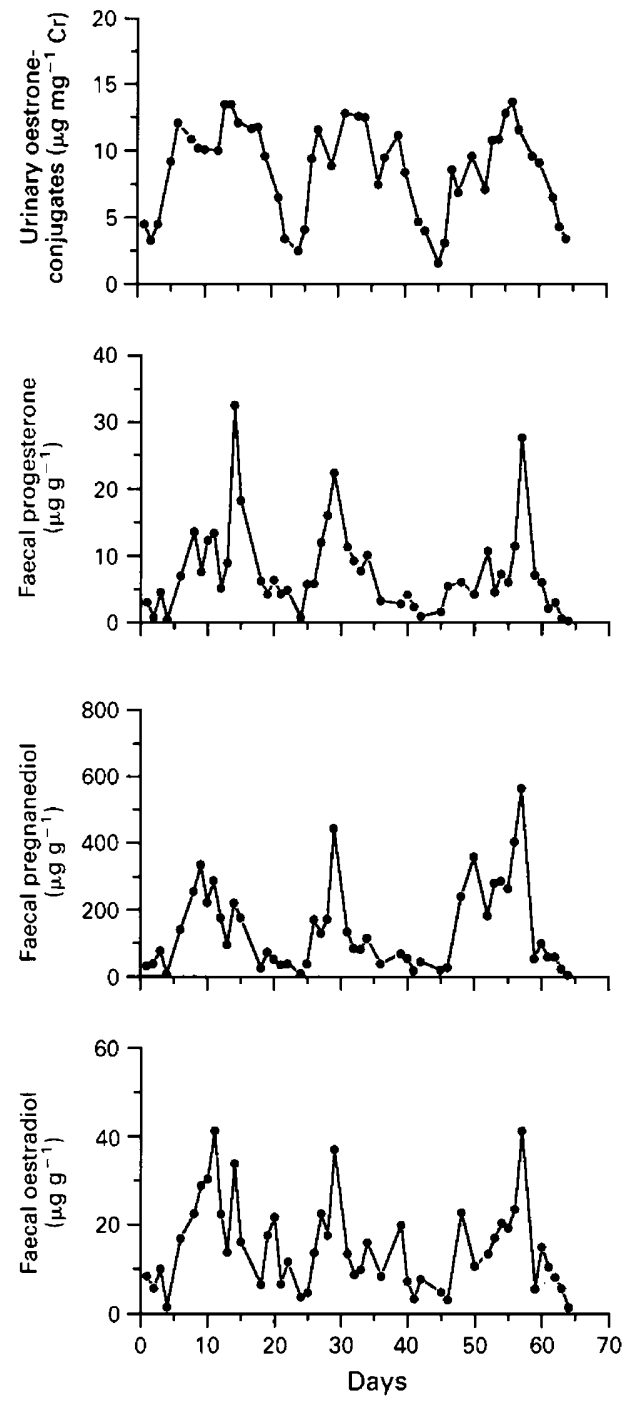

Fig. 5. Hormonal profiles of immunoreactive urinary oestrone conjugates and immunoreactive faecal progesterone, pregnanediol and oestradiol during three consecutive ovarian cycles in a female cotton-top tamarin.

A luteal phase increase in oestrogen excretion is well described in callitrichid primates from descriptions of urinary hormone profiles (Hodges and Eastman, 1984; Ziegler et al., 1987, 1990; French et al., 1992), and it would therefore appear that both urinary and faecal measurements serve principally to monitor post-ovulatory rather than pre-ovulatory events. The more variable excretion of oestrogens into the faeces of the two Saguinus species, despite clearly defined luteal phase increases in urinary concentrations (Ziegler et al., 1987; Tardif and Ziegler, 1992) supports the previous findings of Ziegler et al. (1989) for Saguinus oedipus that circulating oestrogens in Callitrichidae appear to be excreted preferentially into the urine rather than the faeces. Furthermore, the relatively uninformative faecal profiles for these two species may result from the measurement of oestrogens in their unconjugated form when conjugates may instead prevail (see above).

It is clear from a number of studies based on the injection of radiolabelled steroids that a delay of at least $48 \mathrm{~h}$ is often seen between the secretion of a steroid and its appearance in faeces (Shille et al., 1984; Perez et al., 1988; Ziegler et al., 1989). In the present study the interval between the defined rise in plasma progesterone and a significant increase in concentrations of faecal progestins (Callithrix jacchus, Saguinus fuscicollis) was, on average, $48 \mathrm{~h}$, while that between circulating progesterone and faecal oestradiol (Callithrix jacchus) was 2 days longer. This additional delay corresponds to the interval between the luteal phase rise in circulating oestrone-sulfate (the most abundant plasma oestrogen in the marmoset, Harlow et al., 1984) and that of circulating progesterone. It is therefore reasonable to assume that faecal oestradiol derives largely from circulating oestrone sulfate, although the metabolic steps involved are not clear from this study. In this context, it is clear that faecal steroid analysis is of relatively little value in monitoring rapid, short-term changes in hormone concentration and that, with respect to ovulation, the information is first available several days after the event. Interestingly, the termination of luteal function by the use of $\mathrm{PGF}_{2 \alpha}$ in marmosets was much more rapidly reflected by faecal measurements, and oestradiol concentrations returned to follicular phase values within $24 \mathrm{~h}$.

Given adequate samples, the measurement of steroids in faeces appears to be as informative as urine analysis for retrospective determination of ovulation in callitrichid primates. The magnitude of the luteal phase increases in faecal progestins reported here generally exceeded that of urinary steroid metabolites (see Eastman et al., 1984; Ziegler et al., 1987; Tardif and Ziegler, 1992) in all three species. Furthermore, in contrast to the apparent species variation of oestrogen and progestin metabolites in urine (Eastman et al., 1984; Hodges and Eastman, 1984; Heger and Neubert, 1987), faecal pregnanediol immunoreactivity predominated in samples from all three species, thus offering a single approach to monitoring ovarian function in marmosets and tamarins. Thus, faecal steroid analysis not only offers an alternative noninvasive method for reproductive assessment, but also, among Callitrichidae, has the advantage over urine analysis in enabling multispecies application of a single assay methodology for comparative studies.

Although further work is needed to simplify faecal assay methodology and to control for variables such as dietary fibre, food intake and consistency of faeces, the present study demonstrates the potential of faecal hormone analysis for conducting studies into the reproductive and conservation biology of callitrichid primates. The outcome of these future studies may eventually result in more effective management of this endangered family of primates both in captivity and in the wild.

The authors thank C. Casper and D. Blank for care and maintenance of animals and for assistance with sample collection. They also gratefully acknowledge the skilled technical assistance provided by $B$. Baver and J. Hagedorn and the donations of antisera and enzyme label from H. Meyer, M. O. Hoppen and E. Möstl. They are also indebted to C. R. Pryce for generously providing his unpublished data on faecal pregnanediol measurements in marmosets.

\section{References}

Abbott DH (1984) Behavioral and physiological suppression of fertility in subordinate marmoset monkeys American journal of Primatology 6 169-184

Adlercreutz H and Martin F (1976) Oestrogen in human pregnancy faeces Acta Endocrinologica 83 410-419 
Bain JD, Kasman LH, Bercovitz AB and Lasley BL (1984) A comparison of three methods of hydrolysis for estrogen conjugates Steroids $43603-619$

Bamberg E, Choi HS, Möstl E, Wurm W, Lorin D and Arbeiter K (1984) Enzymatic determination of unconjugated oestrogens in faeces for pregnancy diagnosis in mares Equine Veterinary Journal 16 537-539

Bamberg E, Möstl E, Patzl M and King G (1991) Pregnancy diagnosis by enzyme immunoassay of estrogens in feces from nondomestic species joumal of Zoo and Wildife Medicine 22 73-77

Eastman SAK, Makawiti DW, Collins WP and Hodges JK (1984) Pattern of excretion of urinary steroid metabolites during the ovarian cycle and pregnancy in the marmoset monkey Journal of Endocrinology 102 19-26

French JA, De Graw WA, Hendricks SE, Wegner F and Bridson WE (1992) Urinary and plasma gonadotropin concentrations in golden lion tamarins (Leontopithecus r. rosalia) American Joumal of Primatology 26 53-59

Harlow CR, Gems S, Hodges JK and Hearn JP (1983) The relationship between plasma progesterone and the timing of ovulation and early embryonic development in the marmoset monkey Joumal of Zoology 201 273-282

Harlow CR, Hearn JP and Hodges JK (1984) Ovulation in the marmoset monkey: endocrinology, prediction and detection Joumal of Endocrinology 103 17-24

Heger $W$ and Neubert $D$ (1987) Determination of ovulation and pregnancy in the marmoset (Callithrix jacchus) by monitoring of urinary hydroxypregnanolone excretion Journal of Medical Primatology 16 151-164

Heistermann M, Kleis E, Pröve E and Wolters H-J (1989) Fertility status, dominance, and scent marking behavior of family-housed female cotton-top tamarins (Saguinus oedipus) in absence of their mothers American Journal of Primatology 18 177-189

Hodges JK (1992) Detection of oestrous cycles and timing of ovulation Symposia of the Zoological Society of London 64 73-88

Hodges JK Determining and manipulating female reproductive parameters. In Wild Mammals in Captivity Ed. DG Kleiman. University of Chicago Press, Chicago (in press)

Hodges JK and Eastman SAK (1984) Monitoring ovarian function in marmosets and tamarins by the measurement of urinary estrogen metabolites American Joumal of Primatology 6 187-197

Hodges JK and Green DJ (1989) The development of an enzyme-immunoassay for urinary pregnanediol-3-glucuronide and its application to reproductive assessment in exotic mammals journal of Zoology 219 89-99

Hodges JK, Brand HM, Henderson C and Kelly RW (1983) Levels of circulating and urinary oestrogens during pregnancy in the marmoset monkey (Callithrix jacchus) Journal of Reproduction and Fertility 67 73-82

Hodges JK, Green DJ, Cottingham PG, Sauer MJ, Edwards D and Lightman SL (1988) Induction of luteal regression in the marmoset monkey (Callithrix jacchus) by a gonadotrophin releasing hormone antagonist and the effects on subsequent follicular development Journal of Reproduction and Fertility 82 743-752

Jeffcoate SL (1983) Use of rapid hormone assays in the prediction of ovulation. In Ovulation: Methods for its Prediction and Detection pp 67-82 Ed. SL Jeffcoate. John Wiley \& Sons Ltd, Chichester
Lasley BL (1985) Methods for evaluating reproductive function in exotic species Advances in Veterinary Science and Comparative Medicine 30 209-228

Lasley BL and Kirkpatrick JF (1991) Monitoring ovarian function in captive and free-ranging wildlife by means of urinary and faecal steroids Journal of Zoo and Wildlife Medicine 22 23-31

Meyer HHD, Sauerwein H and Mutayoba BM (1990) Immunoaffinity chromatography and a biotin-streptavidin amplified enzymeimmunoassay for sensitive and specific estimation of estradiol-17 $\beta$ Joumal of Steroid Biochemistry 35 263-269

Mittermeier RA, Rylands AB and Coimbra-Filho GAB (1988) Ecology and Behavior of Neotropical Primates (Vol. 2) World Wildlife Fund, Washington

Perez L, Czekala NM, Weisenseel A and Lasley BL (1988) Excretion of radiolabeled estradiol metabolites in the slow loris (Nycticebus coucang) American Journal of Primatology 16 321-330

Risler L, Wasser SK and Sackett GP (1987) Measurement of excreted steroids in Macaca nemestrina American Journal of Primatology 12 91-100

Sachs L (1975) Angewandte Statistik. Springer-Verlag, Berlin

Safar-Hermann N, Ismail MN, Choi HS, Möstl E and Bamberg E (1987) Pregnancy diagnosis in zoo animals by estrogen determination in feces Zoo Biology 6 189-193

Shideler SE, Ortuño AM, Morán FM, Moorman EA and Lasley BL (1993) Simple extraction and enzyme immunoassays for estrogen and progesterone metabolites in the feces of Macaca fascicularis during non-conceptive and conceptive ovarian cycles Biology of Reproduction 48 1290-1298

Shille VM, Wing AE, Lasley BL and Banks JA (1984) Excretion of radiolabeled estradiol in the cat (Felis catus, L): A preliminary report Zoo Biology 3 201-209

Summers PM, Wennink CJ and Hodges JK (1985) Cloprostenol-induced luteolysis in the marmoset monkey (Callithrix jacchus) Journal of Reproduction and Fertility 73 133-138

Tardif SD and Ziegler TE (1992) Features of female reproductive senescence in tamarins (Saguinus spp.), a New World primate Journal of Reproduction and Fertility 94 411-421

Wasser SK, Risler $\mathcal{L}$ and Steiner RA (1988) Excreted steroids in primate feces over the menstrual cycle and pregnancy Biology of Reproduction 39 862-872

Wasser SK, Monfort SL and Wildt DE (1991) Rapid extraction of faecal steroids for measuring reproductive cyclicity and early pregnancy in free-ranging yellow baboons (Papio cynocephalus cynocephalus) Journal of Reproduction and Fertility 92 415-423

Ziegler TE, Savage A, Scheffler G and Snowdon CT (1987) The endocrinology of puberty and reproductive functioning in female cotton-top tamarins (Saguinus oedipus) under varying social conditions Biology of Reproduction 37 618-627

Ziegler TE, Sholl SA, Scheffler G, Haggerty MA and Lasley BL (1989) Excretion of estrone, estradiol, and progesterone in the urine and feces of the female cotton-top tamarin (Saguinus oedipus oedipus) American Joumal of Primatology 17 185-195

Ziegler TE, Snowdon CT and Bridson WE (1990) Reproductive performance and excretion of urinary estrogens and gonadotropins in the female pygmy marmoset (Cebuella pygmaea) American Journal of Primatology 22 191-203 